\title{
Glucocerebrosidase involvement in Parkinson disease and other synucleinopathies
}

\section{Maria do Rosário Almeida*}

Neurogenetics Laboratory, Center for Neuroscience and Cell Biology, University of Coimbra, Coimbra, Portugal

\section{Edited by:}

João Massano, Centro Hospitalar de São João, Portugal

\section{Reviewed by:}

Miryam Carecchio, Azienda

Ospedaliero-Universitaria Maggiore della Carità, Italy

Núria Setó-Salvia, HSCSP, Spain

\section{*Correspondence:}

Maria do Rosário Almeida,

Neurogenetics Laboratory, Center for

Neuroscience and Cell Biology,

University of Coimbra, Largo

Marquês de Pombal, 3004-517

Coimbra, Portugal.

e-mail:mralmeida2008@gmail.com
Mutations in both copies (homozygous or compound heterozygous) of the gene encoding the lysosomal enzyme glucocerebrosidase, which cleaves the glycolipid glucocerebroside into glucose and ceramide cause Gaucher disease. However, multiple independent studies have also reported an association between GBA mutations and Parkinsonism with an increased frequency of heterozygous GBA mutations in various cohorts of patients with parkinsonism and other Lewy body disorders. Furthermore, GBA mutation carriers exhibit diverse parkinsonian phenotypes and present a diffuse pattern of Lewy body distribution in the cerebral cortex. This review provides an overview of the genetic basis for this association in various diseases with dysfunction of the central nervous system in which affected individuals developed Parkinsonian symptoms. The emerging clinical, pathological, and genetic studies in neuronal synucleinopathies suggest a common underlying mechanism in the etiology of these neurodegenerative disorders.

Keywords: glucocerebrosidase gene, Parkinson disease, synucleinopathies, Lewy body pathology

\section{INTRODUCTION}

\section{GAUCHER DISEASE}

Mutations in the glucocerebrosidase gene (OMIM \#606463), which encodes the lysosomal enzyme glucocerebrosidase, which breaks down the glycolipid glucocerebroside (also called glucosylceramide) into glucose and ceramide, result in Gaucher disease (GD; Brady et al., 1965). This is the most common lysosomal storage disorder (LSD) and follows an autosomal recessive mode of inheritance. The accumulation of glucosylceramide primarily occurs in cells of the reticulo endothelial system. The classic cellular hallmark of Gaucher patients is the characteristic morphology of their macrophages with a "wrinkled tissue paper" appearance on cytoplasm, which contains lysosomal inclusion bodies, referred as Gaucher cells (Westbroek et al., 2011). These macrophages accumulate in the liver, spleen, and bone marrow, and patients can present with organomegaly (Beutler and Grabowski, 2001; Sidransky, 2004). Patients with GD can present with a broad range of phenotype and the spectrum of the disease correlates, at least in part, with residual enzyme activity (Cox and Schofield, 1997). Based on the age at onset and neurological manifestations, the disease is classified into three subtypes (type 1, OMIM \#230800; type 2, OMIM \#230900; and type 3, OMIM \#2301000; Velayati et al., 2010). The most common phenotype is non-neuronopathic type 1, sometimes referred as "adult Gaucher disease," although it can affect individuals of all ages. There is enough residual enzyme activity to prevent subtract storage in other cells rather than macrophages. Type $1 \mathrm{GD}$ is relatively common in all ethnic groups, it presents the highest carrier frequency among Ashkenazi Jews population of 1 in 15 and an incidence of about 1 in 1,000. Although type 1 disease is traditionally considered non-neuronopathic, a subset of patients developed neurological alterations and subclinical peripheral neuropathy (Capablo et al., 2008). Patients with neuronopathic forms of the disease, present with either an acute course (type 2) or subacute course (type 3 ). Type 2 phenotype is the most severe form, often presenting in the first 6 months of life and the complete deficiency in glucocerebrosidase activity result in glucosylceramide accumulation in a variety of cell types, including neurons, which leads to rapidly fatal consequences either prenatally or shortly after birth (Cox and Schofield, 1997; Sidransky, 2004). Elevations in brain glucosylsphingosine have been detected in patients with neuronopathic GD, but not with type 1 (Orvisky et al., 2002). Type 3 tends to progress more slowly than type 2 and usually appears in adolescence. Affected individuals may survive into their 30 years. While not limited to any particular ethnic group, the largest group of patients with GD type 3 has been reported from the province of Norrbotten in Sweden (Dahl et al., 1990) and increased prevalence rates have also been reported in Japan and Spain. Although the GBA genotype plays a role in determining the type of GD, genotype-phenotype correlations are difficult to be established, due to the enormous clinical variation concerning the disease manifestations, clinical course, and response to therapy exhibited between patients who share the same genotype (Lachmann et al., 2004; Sidransky, 2004). Differences are even observed among siblings and twins (Amato et al., 2004; Lachmann et al., 2004).

\section{GLUCOCEREBROSIDASE GENE (GBA)}

The human GBA gene is located on chromosome 1q21 and is composed by 11 exons and 10 introns, spanning $7.6 \mathrm{~kb}$ of sequence. A highly homologous pseudogene (GBAP) is located $16 \mathrm{~kb}$ downstream and is $5.7 \mathrm{~kb}$ in length (Horowitz et al., 1989). The presence of this highly homologous pseudogene at the same locus, which shares $96 \%$ exonic sequence homology explains the high number of complex recombinant alleles between $G B A$ and GBAP which have been detected in several GD, Parkinson's disease (PD), or Lewy body dementia (LBD) patients (Hruska et al., 2008). 
To date, approximately 300 pathogenic mutations scattered throughout the GBA gene have been reported and their frequency varies significantly according to the different ethnicity. For example, the common c.1226A $>$ G (N370S) allele is quite frequent among patients of European, American, and Middle East origin and it is not seen in Chinese and Japanese cohorts. Moreover, this particular mutation accounts for approximately $70 \%$ of the mutant alleles in an Ashkenazi Jewish subjects with type 1 GD and with c.84dupG mutation accounts for about $10 \%$. Therefore, focusing the mutation analysis only to these two mutations in Ashkenazi Jewish populations of GD type 1 could be considered a cost-effective procedure. However to other non-Ashkenazi Jewish populations, especially in patients with neuronopathic GD forms, the whole gene sequencing is required for an accurate genotyping (Hruska et al., 2008). Furthermore, to populations of European origin, two mutations, N370S and L444P contribute to two-thirds of the disease alleles found (Kaplan et al., 2006; Hruska et al., 2008). The allelic distribution of these two prevalent mutant alleles can be confused because many laboratories do not distinguish between the point mutation c.1448T $>\mathrm{C}$ (L444P) and recombinant alleles that include this mutation such as RecNciI (Hruska et al., 2008).

\section{GAUCHER DISEASE AND PARKINSONISM}

Clinical reports of patients with GD recognized a small subset of patients who develop parkinsonian symptoms including tremor, rigidity, and bradykinesia (Neudorfer et al., 1996; Machaczka et al., 1999; Bembi et al., 2003). In the majority of these cases, the onset of parkinsonian manifestations was noted in their 40 years, and cognitive changes had also occurred (Tayebi et al., 2003). Postmortem brain tissue of several of these subjects was examined, and Lewy bodies appeared in cortical areas corresponding to Braak stages 56 , in addition to the classic PD pathology (Neumann et al., 2009). The substantia nigra showed a marked loss of pigmented neurons while numerous Lewy bodies were detected and were specifically associated with brain regions affected by GD, including the CA4CA2 hippocampal regions (Wong et al., 2000, 2004). In order to investigate the underlying dopaminergic dysfunction in $G B A$ mutation carriers with and without parkinsonism, Kono et al. (2010) used positron emission tomography (PET) and demonstrated presynaptic dopaminergic dysfunction in the GBA carriers with parkinsonism identical to PD.

Moreover, a higher frequency of PD has also been reported in relatives of patients with GD, many of whom were demonstrated to harbor a heterozygous mutation in GBA. Families of probands with GD were surveyed for the presence of PD among obligate GBA carriers, and a higher rate of PD has been observed compared to the putatively non-carriers cohort. These clinical observations, strengthen the association between these two disorders and provided evidence that mutant glucocerebrosidase, even in heterozygosity may be a risk factor for the development of parkinsonism (Goker-Alpan et al., 2004; Halperin et al., 2003). Furthermore, a recent study was able to estimate the PD penetrance in GBA mutation carriers. The authors considered $G B A$ as a dominant causal gene with reduced penetrance which should be taken into consideration for genetic counseling in relatives of patients with GD and patients with GBA associated PD (Anheim et al., 2012).

\section{GBA MUTATIONS IN PD COHORTS}

The clinical observations of GD patients and their relatives prompted an examination of the GBA mutations among different cohorts of PD worldwide. The first description of the relationship between alterations in the GBA and PD has reported alterations in GBA in $12(21 \%)$ autopsy samples of PD patients. These alterations were more frequent among the younger subjects. These included eight with mutations (N370S, L444P, K198T, and R329C) and four with probable polymorphisms (T369M and E326K; Lwin et al., 2004). Subsequently, the six GBA mutations (N370S, L444P, 84GG, IVS + 1, V394L, and R496H) which are most common among Ashkenazi Jews were screened for a clinic-based case series of 99 Ashkenazi patients with idiopathic PD and 1,543 healthy Ashkenazi Jews. Mutations were found in $31.3 \%$ of $\mathrm{PD}$ patients versus $6.2 \%$ of controls $(P<0.001)$. Once more, patients who were carriers of $G B A$ mutations were younger than those who were not carriers (Aharon-Peretz et al., 2004).

Since then, multiple studies were conducted, in which these findings were replicated in various cohorts of PD patients with different geographical or ethnical origins. These studies reported higher $G B A$ mutation frequencies among the Ashkenazi Jewish PD population, which varied in different centers, between 10.7 and $31.3 \%$ contrasting, with the lowest carrier frequency reported, $2.3 \%$ in a series of Norwegian patients with PD versus $1.7 \%$ in controls (Toft et al., 2006). To accurately ascertain the frequency of $G B A$ mutations in Europe, several European non-Ashkenazi Jewish individuals with $\mathrm{PD}$ and ethnicity-matched controls were screened and GBA alterations have been found in $6.1 \%$ of Portuguese (Bras et al., 2009), 9.8\% of Spanish (Setó-Salvia et al., 2011), 4.2\% British (Neumann et al., 2009), 4.7\% of Greek (Kalinderi et al., 2009), 6.7\% of French (Lesage et al., 2010), and $2.8 \%$ of Italian (De Marco et al., 2008). Importantly, some of the previous studies have focused the mutation analysis only in the two most common mutations, N370S and L444P, whereas some others extended the mutations search to the entire coding region of the gene. Overall, the definitive study on this topic was published in 2009, when an international collaborative study of $G B A$ mutations in PD patients was undertaken by pooling data for individual persons from 16 centers, in 12 countries, including 5,691 patients and 4,898 controls. The data collected demonstrated a strong association between GBA mutations and PD. This finding was not exclusive to a specific ethnic group or a specific $G B A$ mutation. In addition, the age at onset of PD was found to be significantly lower among patients with $G B A$ mutations as compared with those without mutations $(P<0.001$; Sidransky et al., 2009).

Concordant results have been observed in familial PD cases. A large comprehensive study of all GBA exons in one patient with PD from each of 96 PD families selected, based on the familyspecific lod scores at the GBA locus revealed nine different variants identified in 21 of the $96 \mathrm{PD}$ cases $(21.8 \%)$. These variants have been further tested in 1,325 PD cases from 566 multiplex PD families and in 359 controls and were present in 161 of these patients (12.2\%) versus 5.3\% of controls (Nichols et al., 2009). Similarly, a Japanese group identified eight multiplex PD families with patients with PD heterozygous for pathogenic mutations in GBA (Mitsui et al., 2009). Therefore, it is conceivable that GBA 
mutations underlie not only sporadic PD but also familial PD, and are associated with significantly earlier age at onset of disease.

\section{GBA MUTATIONS IN OTHER SYNUCLEINOPATHIES}

There is a line of evidence for the association of GBA mutations with other synucleinopathies rather than $\mathrm{PD}$, such as dementia with Lewy bodies (DLB) and Lewy body variant Alzheimer disease (LBV-AD) but not in multiple-system atrophy (MSA).

Initially, Goker-Alpan et al. (2006) performed full genotyping of GBA in DNA from brain samples of 75 autopsy cases with pathologically confirmed Lewy body disorders including $28 \mathrm{PD}, 35$ cortical LBs (DLB or LBV-AD), and 12 MSA. Mutations in GBA gene were identified in $4 \%$ of cases with $\mathrm{PD}, 23 \%$ of cortical LBs, and none with MSA. A low frequency of GBA mutations, similar between cases $(0.9 \%)$ and controls $(1.2 \%)$ was also reported in a series of 108 British MSA pathologically confirmed cases and 257 controls (Neumann et al., 2009). Similarly, two additional studies did not identify GBA pathogenic mutations among MSA patients. One of the studies involved the sequencing of GBA in $27 \mathrm{MSA}$ cases (Nishioka et al., 2011) and in the other one, the two most common mutations, L444P and N370S were tested in 66 MSA cases (Jamrozik et al., 2009). These data suggested a different mechanism to the $\alpha$-synuclein aggregation in MSA cases in which its principal cellular target is the oligodendrocytes. The evolved concept that MSA may not just be related to PD but also share traits with the family of demyelinating disorders has been recently reviewed (Wenning et al., 2008).

As with the first study, an increased frequency of $G B A$ mutations has also been detected in 2 (3.5\%) of 57 clinical DLB patients of European Caucasian ancestry compared with control subjects (0.4\%; Mata et al., 2008). In this latter study, only the two mutations, N370S and L444P were tested. Also, Farrer et al. (2009) reported mutations in $G B A$ in $6 \%$ of 50 brain samples from subjects with pathologically confirmed diffuse LBD. Conversely, another study found GBA mutations in 28\% (27 of 95) of patients with primary pathological diagnoses of LB disorders, compared with $10 \%$ (6 of 60 ) of cases with primary $\mathrm{AD}$ and $3 \%$ ( 1 of 32 ) of control cases (Clark et al., 2009). In this latter study, the presence of $G B A$ mutations appeared to be related more to the presence of cortical LBs than to LBs confined to the subcortical regions. Moreover, GBA mutations were also detected in 6.8\% (4/59) of cases with a pathological diagnosis of diffuse Lewy body disease. Taken with previous studies, it appears that GBA mutations are associated with a more diffuse pattern of Lewy body distribution involving the cerebral cortex than the brainstem/limbic distribution observed in typical PD (Nishioka et al., 2011). Also Setó-Salvia et al. (2011) reported more recently, 12\% of LBD brains carrying a mutated GBA allele.

\section{GBA MUTATIONS AND COGNITIVE DECLINE}

Given the distribution of Lewy bodies into the neocortical regions, subsequently studies were conducted to rule out the influence of GBA mutations in the clinical course of PD, including cognitive decline and dementia. A prospectively evaluation at the NIH Clinical Center with detailed neurological examinations reported cognitive changes in half of the subjects (Goker-Alpan et al., 2008). In addition, the clinical features of a British $\mathrm{PD}$ patient group who carried GBA mutations comprised, an early-onset of the disease, the presence of hallucinations in $45 \%$ (14/31) and symptoms of cognitive decline or dementia in $48 \%(15 / 31)$ of the patients (Neumann et al., 2009). The effect of GBA on susceptibility to dementia was reinforced in Spanish PD patients with GBA mutations, in which half of the patients developed dementia during the clinical course of PD (Setó-Salvia et al., 2011).

\section{OTHER LYSOSOMAL STORAGE DISORDERS AND PARKINSONISM}

Glucocerebrosidase has been identified as a component of the Lewy body's inclusions in patients with GBA mutations (GokerAlpan et al., 2010) and it colocalized with lysosomal-associated membrane protein 1 (LAMP1) marker, which suggested an impairment of the lysosomal activity in LB pathology. This observation is supported by the emerging reports of $\mathrm{PD}$ across a range of LSDs. Over two-thirds of LSDs involve central nervous system dysfunction (progressive cognitive and motor decline) whereas affected individuals developed frequently parkinsonism with deposits of $\alpha$-synuclein in the brain and substantia nigra pathology (Shachar et al., 2011; Schultz et al., 2011). For the first time, it was recently demonstrated accumulation of the $\alpha$-synuclein in the cortical tissue of two postmortem cases of Sanfilippo syndrome (mucopolysaccharidosis type III, MPSIII; Winder-Rhodes et al., 2012). MPSIII is an autosomal recessive neurodegenerative storage disease caused by mutations in $\mathrm{N}$-acetylglucosaminidase $(N A G L U)$ gene. Additional case reports of LSDs have described parkinsonism features among patients and in postmortem tissues, Lewy body's inclusions have been observed. Thus, patients with GM1 gangliosidosis (caused by defective $\beta$-galactosidase activity), GM2 gangliosidoses, including Tay-Sachs and Sandhoff diseases (caused by defective $\beta$-hexosaminidase activity) and Fabry-Anderson disease (caused by the defective activity of $\alpha$ galactosidase) as well as some family members, developed various PD symptoms including bradykinesia, rigidity, and resting tremor (Argov and Navon, 1984; Inzelberg and Korczyn, 1994; Orimo et al., 1994; Muthane et al., 2004; Roze et al., 2005).

Also relatives and patients with Niemann-Pick $\mathrm{C}$ disease (caused by the defective activity of either NPC1 or NPC2) presented with parkinsonian tremor and an $\alpha$-synucleinopathy in human NPC brain was observed in the midbrain and amygdale of a postmortem tissue (Saito et al., 2004).

Therefore, the link of PD and LSDs suggested a common underlying mechanism compromising the lysosomal and proteasomal degrading systems, resulting to the $\alpha$-synuclein pathology shared by several of these disorders (Settembre et al., 2008). This association, as described above is not limited exclusively to changes that occur in GD, such as changes in glucocerebrosidase activity or in glucosylceramide levels, but rather include changes that might be common to a wide variety of LSDs. So it may be interesting in a near future to investigate the frequency of mutations in genes encoding lysosomal proteins in the patients who display Parkinson's symptoms.

\section{GBA MUTATIONS AND CERAMIDE METABOLISM}

Although $G B A$ mutations and consequently glucocerebrosidase deficiency show a clear and, potentially direct risk association with $\alpha$-synucleinopathies and PD, it was suggested that this link is 
due to its subtract accumulation, glucosylceramide excess, rather than the decrease levels of its subproduct, ceramide. Several studies have been conducted and no evidence of ceramide deficiency has been detected in patients with GD, even in those severely affected. This finding supported the existence of a tightly regulated ceramide levels resultant from many different degradative and synthetic pathways. So, the link between GBA heterozygosity and PD or other synucleinopathies may not be determined by ceramide metabolism dysfunction. In fact, the use of inhibitors of the glucocerebrosidase function has been shown to modulate $\alpha$-synuclein levels (Manning-Bog et al., 2009). In addition, the $\alpha$-synuclein aggregation and glucosylceramide accumulation occurred in a chemically induced glucocerebrosidase deficiency. These studies demonstrated a relationship between glucosylceramide accumulation and $\alpha$-synuclein aggregates, and implicate glucosylceramide accumulation as risk factor for the $\alpha$-synucleinopathies (Xu et al., 2010). Nevertheless, it was proposed that the abnormal $\alpha$-synuclein pathology presented in neurodegeneration with brain iron accumulation 1 and 2 (NBAI-1, NBAI-2) caused by mutations in the pantothenate kinase type 2 (PANK2) and phospholipase A2, group VI (PLA2G6) genes, respectively, could be connected to ceramide metabolism (Bras et al., 2008). However, very recently, it was demonstrated that PLA2G6 mutations were the second common genetic cause after PARK2 gene mutation in cohorts of Chinese and Taiwanese young-onset parkinsonism with Chinese ethnicity (Shi et al., 2011; Lu et al., 2012). Additionally, the postmortem study on a series of patients with PLA2G6 mutations, demonstrated widespread $\alpha$-synuclein positive Lewy pathology particularly severe in the neocortex (Paisán-Ruiz et al., 2012). Therefore, in order to rule out the pathogenic mechanism by which, mutations in PLA2G6 gene cause PD, it will be interesting to measure the ceramide levels in these early-onset $P D$ patients carrying mutations in the PLA2G6 gene.

\section{POSSIBLE MECHANISMS LINK GBA AND PD AND $\alpha$-SYNUCLEINOPATHIES}

GBA mutations act as a strong risk factor to $\alpha$-synucleinopathies and Parkinson disease interfering with the clearance of or promote the aggregation of $\alpha$-synuclein. Mazzulli et al. (2011) have shown that intracellular glucosylceramide levels control the formation of soluble toxic $\alpha$-synuclein assemblies in cultured neurons and mouse and human brain, leading to neurodegeneration. The elevation and formation of $\alpha$-synuclein assemblies inhibits the lysosomal activity of normal glucocerebrosidase in neurons and idiopathic PD brain, resulting in additional glucosylceramide accumulation and augmented $\alpha$-synuclein oligomer formation. This self-propagating positive feedback process, proceeds until a pathogenic threshold is reached, resulting in neurodegeneration (Mazzulli et al., 2011). The frequently reported lysosomal proteolytic dysfunction in PD as well is in other LSDs is one of the common mechanisms underlying the $\alpha$-synuclein pathology shared by various of these disorders (Shachar et al., 2011; Yap et al., 2011). Indeed, the disruption of autophagy-lysosomal process has been proposed as the mechanism by which LRRK2 mutations, the gene responsible for the autosomal dominant forms of $\mathrm{PD}$, may exert its effects (Tong et al., 2010). The autophagy degrading pathway is considered the primary mechanism through which $\alpha$-synuclein is degraded and its impairment is reinforced by the involvement of another gene associated with familial forms of PD, ATP13A gene, which encodes a lysosomal ATPase responsible for maintaining intralysosomal $\mathrm{pH}$ and suppresses $\alpha$-synuclein toxicity in C. elegans, yeast, and primary neuronal cultures (Gitler et al., 2009). In addition, the dysfunction of the ubiquitin-proteasome system also underlies many of these $\alpha$-synucleinopathies. Again, Parkin gene which has been associated mostly with the early-onset $\mathrm{PD}$ recessive familial cases encodes the $\mathrm{E} 3$ ubiquitin ligase, and is involved in the ubiquitination pathway of misfolded glucocerebrosidase in dopaminergic neurons. The absence of normal parkin leads to improper degradation of some of its subtracts, such as $\alpha$-synuclein and to their accumulation (Ron et al., 2010).

A distinct $\alpha$-synuclein degraded pathway within lysosomes is the chaperone mediated autophagy (CMA), whereas SNCA mutants Ala53Thr and Ala30Pro bind to LAMP2A but fail to translocate into the lysosomal lumen for breakdown (Cuervo et al., 2004; Cullen et al., 2011). Subsequently, further CMA-mediated degradation substrates are blocked, which contributes to their accumulation (Westbroek et al., 2011). Likewise, defects in mitochondrial activity are reported in many of $\alpha$-synucleinopathies which results mainly in decrease levels of the ATP synthesis, causing the formation of free radicals leading to oxidative stress and impairment of the membrane potential (Schapira, 2011). Several studies have demonstrated the effect of PD causative genes also on mitochondrial depolarization and their interference in the electron transport chain (Schapira and Gegg, 2011).

Additionally, GBA haploinsufficiency alters the lipid metabolism and composition of the cell membranes which is also considered a common impaired pathway in many of these disorders. The helical binding of $\alpha$-synuclein to lipid membranes prevents the formation of fibrillar protein structures. It has been demonstrated that $\alpha$-synuclein does bind to brain-derived glycosphingolipids that contain glucosylceramide in their core. Therefore, deficiency of glucocerebrosidase leads to the accumulation of its substrates glucosylceramide and/or glucosylsphingosine and alter sphingolipid composition of the cell membranes, which may disrupt the membrane binding of $\alpha$-synuclein, enhancing its aggregation in the cytoplasm (DePaolo et al., 2009).

In this article, an extensive literature review has documented clinical, pathological, and genetic studies which have contributed to our growing understanding of the involvement of the glucocerebrosidase as a susceptibility factor to PD and other synucleinopathies. The rapid pace of investigation of the GBA function has been stimulated by the identification of mutations in this gene, not only in GD patients, but also in sporadic and familial PD cohorts as well as in different $\alpha$-synucleinopathies. The clinical and pathological studies have accompanied and complement the genetic analysis of GBA gene in different patient's cohorts, adding a crucial value toward the delineation of the different molecular pathways underlying the pathogenesis of these conditions. Curiously, an attempt to integrate the different molecular pathways and functions in a unique mechanism indicates a considerable overlap between them, suggesting interactions of pathological proteins engaging common downstream pathways which is not only relevant for the familial forms, but also to the more common sporadic PD cases. 


\section{REFERENCES}

Aharon-Peretz, J., Rosenbaum, H., and Gershoni-Baruch, R. (2004). Mutations in the glucocerebrosidase gene and Parkinson's disease in Ashkenazi Jews. N. Engl. J. Med. 351, 1972-1977.

Amato, D., Stachiw, T., Clarke, J. T., and Rivard, G. E. (2004). Gaucher disease: variability in phenotype among siblings. J. Inherit. Metab. Dis. 27, 659-669.

Anheim, M., Elbaz, A., Lesage, S., Durr, A., Condroyer, C., Viallet, F., Pollak, P., Bonaïti, B., Bonaitti-Pellié, C., and Brice, A. on behalf of the French Parkinson Disease Genetic Group. (2012). Penetrance of Parkinson disease in glucocerebrosidase gene mutation carriers. Neurology 78, 417-420.

Argov, Z., and Navon, R. (1984). Clinical and genetic variations in the syndrome of adult GM2 gangliosidosis resulting from hexosaminidase A deficiency. Ann. Neurol. 16, 14-20.

Bembi, B., Zambito Marsala, S., Sidransky, E., Ciana, G., Carrozzi, M., Zorzon, M., Martini, C., Gioulis, M., Pittis, M. G., and Capus, L. (2003). Gaucher's disease with Parkinson's disease: clinical and pathological aspects. Neurology 61, 99-101.

Beutler, E., and Grabowski, G. A. (2001). "Gaucher disease," in The Metabolic and Molecular Bases of Inherited Disease, 8th Edn, eds C. Scriver, A. L. Beaudet, W. S. Sly, and D. Valle (New York: McGraw-Hill), 3635-3668.

Brady, R. O., Kanfer, J., and Shapiro, D. (1965). The metabolism of glucocerebrosides. I. Purification and properties of a glucocerebrosidecleaving enzyme from spleen tissue. J. Biol. Chem. 240, 39-43.

Bras, J., Paisan-Ruiz, C., Guerreiro, R., Ribeiro, M. H., Morgadinho, A., Januario, C., Sidransky, E., Oliveira, C., and Singleton, A. (2009). Complete screening for glucocerebrosidase mutations in Parkinson disease patients from Portugal. Neurobiol. Aging 30, 1515-1517.

Bras, J., Singleton, A., Cookson, M. R., and Hardy, J. (2008). Emerging pathways in genetic Parkinson's disease: potential role of ceramide metabolism in Lewy body disease. FEBS J. 275, 5767-5773.

Capablo, J. L., Saenz de Cabezón, A., Fraile, J., Alfonso, P., Pocovi, M., and Giraldo, P. on behalf of the Spanish Group on Gaucher Disease. (2008). Neurological evaluation of patients with Gaucher disease diagnosed as type 1. J. Neurol. Neurosurg. Psychiatr. 79, 219-222.
Clark, L. N., Kartsaklis, L. A., Wolf Gilbert, R., Dorado, B., Ross, B. M., Kisselev, S., Verbitsky, M., MejiaSantana, H., Cote, L. J., Andrews, H., Vonsattel, J. P., Fahn, S., Mayeux, R., Honig, L. S., and Marder, K. (2009). Association of glucocerebrosidase mutations with dementia with lewy bodies. Arch. Neurol. 66, 578-583.

Cox, T. M., and Schofield, J. P. (1997). Gaucher's disease: clinical features and natural history. Baillieres Clin. Haematol. 10, 657-689.

Cuervo, A. M., Stefanis, L., Fredenburg, R., Lansbury, P. T., and Sulzer, D. (2004). Impaired degradation of mutant alpha-synuclein by chaperone-mediated autophagy. Science 305, 1292-1295.

Cullen, V., Sardi, S. P., Ng, J., Xu, Y. H., Sun, Y., Tomlinson, J. J., Kolodziej, P., Kahn, I., Saftig, P., Woulfe, J., Rochet, J. C., Glicksman, M. A., Cheng, S. H., Grabowski, G. A., Shihabuddin, L. S., and Schlossmacher, M. G. (2011). Acid $\beta$-glucosidase mutants linked to Gaucher disease, Parkinson disease, and Lewy body dementia alter $\alpha$-synuclein processing. Ann. Neurol. 69, 940-953.

Dahl, N., Lagerström, M., Erikson, A., and Pettersson, U. (1990). Gaucher disease type III (Norrbottnian type) is caused by a single mutation in exon 10 of the glucocerebrosidase gene. Am. J. Hum. Genet. 47, 275-278.

De Marco, E. V., Annesi, G., Tarantino, P., Rocca, F. E., Provenzano, G., Civitelli, D., Cirò Candiano, I. C., Annesi, F., Carrideo, S., Condino, F., Nicoletti, G., Messina, D., Novellino, F., Morelli, M., and Quattrone, A. (2008). Glucocerebrosidase gene mutations are associated with Parkinson's disease in southern Italy. Mov. Disord. 23, 460-463.

DePaolo, J., Goker-Alpan, O., Samaddar, T., Lopez, G., and Sidransky, E. (2009). The association between mutations in the lysosomal protein glucocerebrosidase and parkinsonism. Mov. Disord. 24, 1571-1578.

Farrer, M. J., Williams, L. N., Algom, A. A., Kachergus, J., Hulihan, M. M., Ross, O. A., Rajput, A., Papapetropoulos, S., Mash, D. C., and Dickson, D. W. (2009). Glucosidasebeta variations and Lewy body disorders. Parkinsonism Relat. Disord. 15, 414-416.

Gitler, A. D., Chesi, A., Geddie, M. L., Strathearn, K. E., Hamamichi, S., Hill, K. J., Caldwell, K. A., Caldwell, G. A., Cooper, A. A., Rochet, J. C., and Lindquist, S. (2009). Alpha-synuclein is part of a diverse and highly conserved interaction network that includes PARK9 and manganese toxicity. Nat. Genet. 41 , 308-315.

Goker-Alpan, O., Giasson, B. I., Eblan, M. J., Nguyen, J., Hurtig, H. I., Lee, V. M., Trojanowski, J. Q., and Sidransky, E. (2006). Glucocerebrosidase mutations are an important risk factor for Lewy body disorders. Neurology 67, 908-910.

Goker-Alpan, O., Lopez, G., Vithayathil, J., Davis, J., Hallett, M., and Sidransky, E. (2008). The spectrum of parkinsonian manifestations associated with glucocerebrosidase mutations. Arch. Neurol. 65, 1353-1357.

Goker-Alpan, O., Schiffmann, R., LaMarca, M. E., Nussbaum, R., McInerney-Leo, A., and Sidransky, E. (2004). Parkinsonism among Gaucher disease carriers. J. Med. Genet. 41, 937-940.

Goker-Alpan, O., Stubblefield, B. K., Giasson, B. I., and Sidransky, E. (2010). Glucocerebrosidase is present in alpha-synuclein inclusions in Lewy body disorders. Acta Neuropathol. 120, 641-649.

Halperin, A., Elstein, D., and Zimran, A. (2003). Increased incidence of Parkinson disease among relatives of patients with Gaucher disease. Blood Cells Mol. Dis. 36, 426-428.

Horowitz, M., Wilder, S., Horowitz, Z., Reiner, O., Gelbart, T., and Beutler, E. (1989). The human glucocerebrosidase gene and pseudogene: structure and evolution. Genomics 4, 87-96.

Hruska, K. S., LaMarca, M. E., Scott, C. R., and Sidransky, E. (2008). Gaucher disease: mutation and polymorphism spectrum in the glucocerebrosidase gene (GBA). Hum. Mutat. 29, 567-583.

Inzelberg, R., and Korczyn, A. D. (1994). Parkinsonism in adult-onset GM2 gangliosidosis. Mov. Disord. 9, 375-377.

Jamrozik, Z., Lugowska, A., Slawek, J., and Kwiecinski, H. (2009). Glucocerebrosidase mutations p.L444P and p.N370S are not associated with multisystem atrophy, progressive supranuclear palsy and corticobasal degeneration in Polish patients. J. Neurol. 257, 459-460.

Kalinderi, K., Bostantjopoulou, S. Paisan-Ruiz, C., Katsarou, Z., Hardy, J., and Fidani, L. (2009). Complete screening for glucocerebrosidase mutations in Parkinson disease patients from Greece. Neurosci. Lett. 452, 87-89.

Kaplan, P., Andersson, H. C., Kacena, K. A., and Yee, J. D. (2006). The clinical and demographic characteristics of nonneuronopathic Gaucher disease in 887 children at diagnosis. Arch Pediatr. Adolesc. Med. 160, 603-608.

Kono, S., Ouchi, Y., Terada, T., Ida, H., Suzuki, M., and Miyajima, H. (2010). Functional brain imaging in glucocerebrosidase mutation carriers with and without Parkinsonism. Mov. Disord. 25, 1823-1829.

Lachmann, R. H., Grant, I. R., Halsall, D., and Cox, T. M. (2004). Twin pairs showing discordance of phenotype in adult Gaucher's disease. QJM 97, 199-204.

Lesage, S., Anheim, M., Condroyer, C., Pollak, P., Durif, F., Dupuits, C., Viallet, F., Lohmann, E., Corvol, J. C. Honoré, A., Rivaud, S., Vidailhet, M., Dürr, A., and Brice, A. for the French Parkinson's Disease Genetics Study Group. (2010). Large-scale screening of the Gaucher's diseaserelated glucocerebrosidase gene in Europeans with Parkinson's disease. Hum. Mol. Genet. 20, 202-210.

Lu, C. S., Lai, S. C., Wu, R. M., Weng, Y. H., Huang, C. L., Chen, R. S., Chang, H. C., Wu-Chou, Y. H., and Yeh, T. H. (2012). PLA2G6 mutations in PARK14linked young-onset parkinsonism and sporadic Parkinson's disease. Am. J. Med. Genet. B Neuropsychiatr. Genet. 159B, 183-191.

Lwin, A., Orvisky, E., Goker-Alpan, O., LaMarca, M. E., and Sidransky, E. (2004). Glucocerebrosidase mutations in subjects with parkinsonism. Mol. Genet. Metab. 81, 70-73.

Machaczka, M., Rucinska, M., Skotnicki, A. B., and Jurczak, W. (1999). Parkinson's syndrome preceding clinical manifestation of Gaucher's disease. Am. J. Hematol. 61, 216-217.

Manning-Bog, A. B., Schule, B., and Langston, J. W. (2009). Alphasynuclein glucocerebrosidase interactions in pharmacological Gaucher models: a biological link between Gaucher disease and parkinsonism. Neurotoxicology 30, 1127-1132.

Mata, I. F., Samii, A., Schneer, S. H., Roberts, J. W., Griffith, A., Leis, B. C., Schellenberg, G. D., Sidransky, E., Bird, T. D., Leverenz, J. B., Tsuang, D., and Zabetian, C. P. (2008). Glucocerebrosidase gene mutations: a risk factor for Lewy body disorders. Arch. Neurol. 65, 379-382.

Mazzulli, J. R., Xu, Y. H., Sun, Y., Knight, A. L., McLean, P. J., Caldwell, G. A., Sidransky, E., Grabowski, G. A., and Krainc, D. (2011). Gaucher disease glucocerebrosidase and a-synuclein form a bidirectional pathogenic loop in synucleinopathies. Cell 146, 37-52.

Mitsui, J., Mizuta, I., Toyoda, A., Ashida, R., Takahashi, Y., Goto, J., Fukuda, 
Y., Date, H., Iwata, A., Yamamoto, M., Hattori, N., Murata, M., Toda, T., and Tsuji, S. (2009). Mutations for Gaucher disease confer high susceptibility to Parkinson disease. Arch. Neurol. 66, 571-576.

Muthane, U., Chickabasaviah, Y., Kaneski, C., Shankar, S. K., Narayanappa, G., Christopher, R., and Govindappa, S. S. (2004). Clinical features of adult GM1 gangliosidosis: report of three Indian patients and review of 40 cases. Mov. Disord. 19, 1334-1341.

Neudorfer, O., Giladi, N., Elstein, D., Abrahamov, A., Turezkite, T., Aghai, E., Reches, A., Bembi, B., and Zimran, A. (1996). Occurrence of Parkinson's syndrome in type I Gaucher disease. QJM 89, 691-694.

Neumann, J., Bras, J., Deas, E., O'Sullivan, S. S., Parkkinen, L., Lachmann, R. H., Li, A., Holton, J., Guerreiro, R., Paudel, R., Segarane, B., Singleton, A., Lees, A., Hardy, J., Houlden, H., Revesz, T., and Wood, N. W. (2009). Glucocerebrosidase mutations in clinical and pathologically proven Parkinson's disease. Brain 132, 1783-1794.

Nichols, W. C., Pankratz, N., Marek, D. K., Pauciulo, M. W., Elsaesser, V. E., Halter, C. A., Rudolph, A., Wojcieszek, J., Pfeiffer, R. F., and Foroud, T. for the Parkinson Study Group-PROGENI Investigators. (2009). Mutations in GBA are associated with familial Parkinson disease susceptibility and age at onset. Neurology 72, 310-316.

Nishioka, K., Ross, O. A., Vilariño-Güell, C., Cobb, S. A., Kachergus, J. M., Mann, D. M., Snowden, J., Richardson, A. M., Neary, D., Robinson, C. A., Rajput, A., Papapetropoulos, S., Mash, D. C., Pahwa, R., Lyons, K. E., Wszolek, Z. K., Dickson, D. W., and Farrer, M. J. (2011). Glucocerebrosidase mutations in diffuse Lewy body disease. Parkinsonism Relat. Disord. 17, 55-57.

Orimo, S., Iwasaki, T., Yoshino, H., Arai, M., and Hiyamuta, E. (1994). Na autopsied case of Fabry's disease presenting with parkinsonism and cardiomegaly as a cardinal clinical manifestation. Rinsho Shinkeigaku 34, 1003-1007.

Orvisky, E., Park, J. K., LaMarca, M. E., Ginns, E. I., Martin, B. M., Tayebi, N., and Sidransky, E. (2002). Glucosylsphingosine accumulation in tissues from patients with Gaucher disease: correlation with phenotype and genotype. Mol. Genet. Metab. 76, 262-270.

Paisán-Ruiz, C., Li, A., Schneider, S. A., Holton, J. L., Johnson, R., Kidd, D., Chataway, J., Bhatia, K. P., Lees, A. J.,
Hardy, J., Revesz, T., and Houlden, H. (2012). Widespread Lewy body and tau accumulation in childhood and adult onset dystonia-parkinsonism cases with PLA2G6 mutations. Neurobiol. Aging 33, 814-823.

Ron, I., Rapaport, D., and Horowitz, M. (2010). Interaction between parkin and mutant glucocerebrosidase variants: a possible link between Parkinson disease and Gaucher disease. Hum. Mol. Genet. 19, 3771-3781.

Roze, E., Paschke, E., Lopez, N., Eck, T., Yoshida, K., Maurel-Ollivier, A., Doummar, D., Caillaud, C., Galanaud, D., Billette de Villemeur, T., Vidailhet, M., and Roubergue, A. (2005). Dystonia and parkinsonism in GM1 type 3 gangliosidosis. Mov. Disord. 20, 1366-1369.

Saito, Y., Suzuki, K., Hulette, C. M., and Murayama, S. (2004). Aberrant phosphorylation of alpha-synuclein in human Niemann-Pick type C1 disease. J. Neuropathol. Exp. Neurol. 63, 323-328.

Schapira, A. H. (2011). Mitochondrial pathology in Parkinson's disease. $M t$. Sinai J. Med. 78, 872-881.

Schapira, A. H., and Gegg, M. (2011). Mitochondrial contribution to Parkinson's disease pathogenesis. Parkinsons Dis. 2011, 159160.

Schultz, M. L., Tecedor, L., Chang, M., and Davidson, B. L. (2011). Clarifying lysosomal storage diseases. Trends Neurosci. 34, 401-410.

Setó-Salvia, N., Pagonabarraga, J., Houlden, H., Pascual-Sedano, B., Dols-Icardo, O., Tucci, A., PaisánRuiz, C., Campolongo, A., AntónAguirre, S., Martín, I., Muñoz, L., Bufill, E., Vilageliu, L., Grinberg, D., Cozar, M., Blesa, R., Lleó, A., Hardy, J., Kulisevsky, J., and Clarimón J. (2011). Glucocerebrosidase mutations confer a greater risk of dementia during Parkinson's disease course. Mov. Disord. 27, 393-399.

Settembre, C., Fraldi, A., Jahreiss, L., Spampanato, C., Venturi, C., Medina, D., de Pablo, R., Tacchetti, C., Rubinsztein, D. C., and Ballabio, A. (2008). A block of autophagy in lysosomal storage disorders. Hum. Mol. Genet. 17, 119-129.

Shachar, T., Lo Bianco, C., Recchia, A., Wiessner, C., Raas-Rothschild, A., and Futerman, A. H. (2011). Lysosomal storage disorders and Parkinson's disease: Gaucher disease and beyond. Mov. Disord. 26, 1593-1604.

Shi, C. H., Tang, B. S., Wang, L., Lv, Z. Y., Wang, J., Luo, L. Z., Shen, L., Jiang, H., Yan, X. X., Pan, Q., Xia, K., and Guo, J. F. (2011). PLA2G6 gene mutation in autosomal recessive early-onset parkinsonism in a Chinese cohort. Neurology 77, 75-81.

Sidransky, E. (2004). Gaucher disease: complexity in a "simple" disorder. Mol. Genet. Metab. 83, 6-15.

Sidransky, E., Nalls, M. A., Aasly, J. O., Aharon-Peretz, J., Annesi, G., Barbosa, E. R., Bar-Shira, A., Berg, D. Bras, J., Brice, A., Chen, C. M., Clark, L. N., Condroyer, C., De Marco, E. V., Dürr, A., Eblan, M. J., Fahn, S., Farrer, M. J., Fung, H. C., Gan-Or, Z., Gasser, T., Gershoni-Baruch, R., Giladi, N., Griffith, A., Gurevich, T., Januario, C., Kropp, P., Lang, A. E., Lee-Chen, G. J., Lesage, S., Marder, K., Mata, I. F., Mirelman, A., Mitsui, J., Mizuta, I., Nicoletti, G., Oliveira, C., Ottman, R., Orr-Urtreger, A., Pereira, L. V., Quattrone, A., Rogaeva, E., Rolfs, A., Rosenbaum, H., Rozenberg, R., Samii, A., Samaddar, T., Schulte, C., Sharma, M., Singleton, A., Spitz, M., Tan, E. K., Tayebi, N., Toda, T., Troiano, A. R., Tsuji, S., Wittstock, M., Wolfsberg, T. G., Wu, Y. R., Zabetian, C. P., Zhao, Y., and Ziegler, S. G. (2009). Multicenter analysis of glucocerebrosidase mutations in Parkinson's disease. N. Engl. J. Med. 361, 1651-1661.

Tayebi, N., Walker, J., Stubblefield, B., Orvisky, E., LaMarca, M. E., Wong, K., Rosenbaum, H., Schiffmann, R., Bembi, B., and Sidransky, E. (2003). Gaucher disease with parkinsonian manifestations: does glucocerebrosidase deficiency contribute to a vulnerability to parkinsonism? Mol. Genet. Metab. 79, 104-109.

Toft, M., Pielsticker, L., Ross, O. A., Aasly, J. O., and Farrer, M. J. (2006). Glucocerebrosidase gene mutations and Parkinson disease in the Norwegian population. Neurology 66, 415-417.

Tong, Y., Yamaguchi, H., Giaime, E., Boyle, S., Kopan, R., Kelleher, R. J., and Shen, J. (2010). Loss of leucine-rich repeat kinase 2 causes impairment of protein degradation pathways, accumulation of alphasynuclein, and apoptotic cell death in aged mice. Proc. Natl. Acad. Sci. U.S.A. 107, 9879-9884.

Velayati, A., Yu, W. H., and Sidransky, E. (2010). The role of glucocerebrosidase mutations in Parkinson disease and Lewy body disorders. Curr. Neurol. Neurosci. Rep. 10, 190-198.

Wenning, G. K., Stefanova, N., Jellinger, K. A., Poewe, W., and Schlossmacher, M. G. (2008). Multiple system atrophy: a primary oligodendrogliopathy. Ann. Neurol. 64, 239-246.

Westbroek, W., Gustafson, A. M., and Sidransky, E. (2011). Exploring the link between glucocerebrosidase mutations and parkinsonism. Trends Mol. Med. 17, 485-493.
Winder-Rhodes, S. E., Garcia-Reitböck, P., Ban, M., Evans, J. R., Jacques, T. S., Kemppinen, A., Foltynie, T., Williams-Gray, C. H., Chinnery, P. F., Hudson, G., Burn, D. J., Allcock, L. M., Sawcer, S. J., Barker, R. A., and Spillantini, M. G. (2012). Genetic and pathological links between Parkinson's disease and the lysosomal disorder Sanfilippo syndrome. Mov. Disord. 27, 312-315.

Wong, K., Sidransky, E., Verma, A., Mixon, T., Sandberg, G. D., Wakefield, L. K., Morrison, A., Lwin, A., Colegial, C., Allman, J. M., and Schiffmann, R. (2004). Neuropathology provides clues to the pathophysiology of Gaucher disease. Mol. Genet. Metab. 82, 192-207.

Wong, K., Topaloglu, H., Tresser, N., and Schiffmann, R. (2000). Dementia with Lewy bodies and Parkinson's disease in a type 1 Gaucher disease patient. J. Neuropathol. Exp. Neurol. 59, 141.

Xu, Y. H., Sun, Y., Ran, H., Quinn, B., Witte, D., and Grabowski, G. A. (2010). Accumulation and distribution of alpha-synuclein and ubiquitin in the CNS of Gaucher disease mouse models. Mol. Genet. Metab. 102, 436-437.

Yap, T. L., Gruschus, J. M., Velayati, A., Westbroek, W., Goldin, E., Moaven, N., Sidransky, E., and Lee, J. C. (2011). Alpha-synuclein interacts with lucocerebrosidase providing a molecular link between Parkinson and Gaucher diseases. J. Biol. Chem. 286, 28080-28088.

Conflict of Interest Statement: The author declares that the research was conducted in the absence of any commercial or financial relationships that could be construed as a potential conflict of interest.

Received: 20 February 2012; paper pending published: 11 March 2012; accepted: 05 April 2012; published online: 27 April 2012.

Citation: Almeida MR (2012) Glucocerebrosidase involvement in Parkinson disease and other synucleinopathies. Front. Neur. 3:65. doi: 10.3389/fneur.2012.00065

This article was submitted to Frontiers in Dementia, a specialty of Frontiers in Neurology.

Copyright (C) 2012 Almeida. This is an open-access article distributed under the terms of the Creative Commons Attribution Non Commercial License, which permits non-commercial use, distribution, and reproduction in other forums, provided the original authors and source are credited. 